\title{
Two Structural Adaptations for Regulating Transmitter Release at Lobster Neuromuscular Synapses
}

\author{
John P. Walrond,' C. K. Govind, ${ }^{2}$ and Sara E. Huestis' \\ 'Department of Anatomy and Neurobiology, Colorado State University, Fort Collins, CO 80523 and '2Life Sciences Division, \\ University of Toronto, 1265 Military Trail, Scarborough, Ontario, Canada M1C 1A4
}

\begin{abstract}
The distal accessory flexor muscle (DAFM) in the lobster (Homarus americanus) walking leg consists of 5 muscle fiber bundles. All five bundles, one proximal, one distal, and 3 medial, are innervated by one excitatory and one inhibitory motor neuron. Both neurons release more transmitter on the distal bundle than on the proximal bundle. The aim of our studies was to investigate the structural basis of this differentiation. Thin sections cut at $\mathbf{5 0} \mu \mathrm{m}$ intervals showed a similar number of excitatory synapses on the two bundles. Freeze-fracture views of excitatory synapses showed that synapse size, active zone number per synapse, and intramembrane particle density in the postsynaptic membrane are similar proximally and distally. Active zones at synapses on the distal bundle are larger and contain about $50 \%$ more large intramembrane particles, which are thought to include the voltage-gated $\mathrm{Ca}^{2+}$ channels that couple the action potential to transmitter release, than their counterparts on the most proximal bundle. This difference in channel number appears to produce a disproportionate increase in the probability of transmitter release sufficient to account for most of the proximal-distal disparity in the amplitude of the excitatory postsynaptic potential. In contrast, staining the inhibitor for antibodies to the inhibitory neurotransmitter, GABA, showed that it forms more varicosities on the distal bundle than on the proximal bundle. Because most of the synapses are located in the varicosities, differences in synapse number likely regulate the proximal-distal disparity in the amount of inhibitory transmitter released. Therefore, the regional differentiation in the amount of transmitter released in the DAFM appears to be based on two distinct mechanisms. In the inhibitor, transmitter release appears to be regulated differentially by differences in synapse number. In the excitor, transmitter release appears to be regulated differentially from a similar number of synapses by differences in active zone structure.
\end{abstract}

IKey words: active zones, active zone particles, calcium channels, crustacean, GABA, freeze-fracture, transmitter release]

\footnotetext{
Received Nov. 2, 1992; revised May 3, 1993; accepted May 20, 1993.

We thank Joanne Pearce and Christine Gee for expert technical assistance, and Brian Evans for his art work and graphics. We wish to express our appreciation to Dr. Gene Delay for assistance in statistical analysis. The freeze-fracture studies were initiated while JPW was an NIH Staff Fellow in the Laboratory of Neurobiology. This research was supported by a National Institutes of Health grant (NS25572) and a National Science Foundation grant (BNS-8719517) to JPW and a grant from the Natural Sciences and Engineering Council of Canada to CKG.

Copyright (C) 1993 Society for Neuroscience $0270-6474 / 93 / 134831-15 \$ 05.00 / 0$
}

The release of neurotransmitter from discrete sites in the axon terminal is the sine qua non of chemical synaptic transmission. These sites, referred to as active zones, are recognizable in thin scctions as presynaptic densities that are apposed to the plasmalemma and flanked by synaptic vesicles (Couteaux and Pecot-Dechavassine, 1970; Heuser and Reese, 1973; Heuser et al., 1974; Heuser et al., 1979; Dickinson-Nelson and Reese, 1983). In freeze-fracture views, active zones at central and peripheral synapses are recognized as arrays of large intramembrane particles (active zone particles) in the protoplasmic leaflet (P-face) of the presynaptic axolemma (Dryer et al., 1973; Heuser et al., 1974; Gulley et al., 1978; Pearce et al., 1986; Roberts et al., 1990). The short delay $(\sim 200 \mu \mathrm{sec})$ between $\mathrm{Ca}^{2+}$ influx and the initiation of transmitter release suggests that the $\mathrm{Ca}^{2+}$ channels that couple the action potential to transmitter release are located within $100 \mathrm{~nm}$ of the release site (Llinás et al., 1981). The size, number, and location of the active zone particles is consistent with their being these $\mathrm{Ca}^{2+}$ channels (Pumplin et al., 1981; Simon and Llinás, 1985; Walrond and Reese, 1985; Roberts et al., 1990). Studies with ion channel-specific toxins indicate that voltage-gated $\mathrm{Ca}^{2+}$ channels and $\mathrm{Ca}^{2+}$-activated $\mathrm{K}+$ channels are both located near the transmitter release sites at frog neuromuscular junctions (Robitaille et al., 1990; Cohen et al., 1991; Robitaille and Charlton, 1992). Electrophysiological studies have mapped these channel types to the base of hair cells in frog where they form synapses with the auditory afferents (Roberts et al., 1990). Active zones were observed in this region in freeze-fracture views, suggesting that both channel types might be localized at the active zone (Roberts et al., 1990). Antibodies from patients with Lambert Eaton Myasthenic Syndrome block voltage-dependent $\mathrm{Ca}^{2+}$ channels (Kim and Neher, 1988), and disrupt active zone structure at mammalian neuromuscular synapses (Engel, 1991).

Several studies have revealed a positive correlation between the amount of transmitter released and the structure of active zones (Atwood and Marin, 1983; Rheuben, 1985; Walrond and Reese, 1985; Propst and Ko, 1987). For example, in the spider crab (Hyas areneas) limb stretcher muscle, the excitor elicits large and small epsp's in muscle fibers adjacent to one another. The axon terminals that elicit the higher amplitude epsp's contain more and larger presynaptic densities than axon terminals that elicit the smaller epsp's (Atwood and Marin, 1983). In the moth (Manduca sexta), the phasic motor axon clicits larger postsynaptic potentials than the tonic axon and correspondingly contains many more intramembrane particles per active zone (Rheuben, 1985). Similarly, high-output, phasic synapses on twitch muscle fibers of lizards contain more active zone particles 


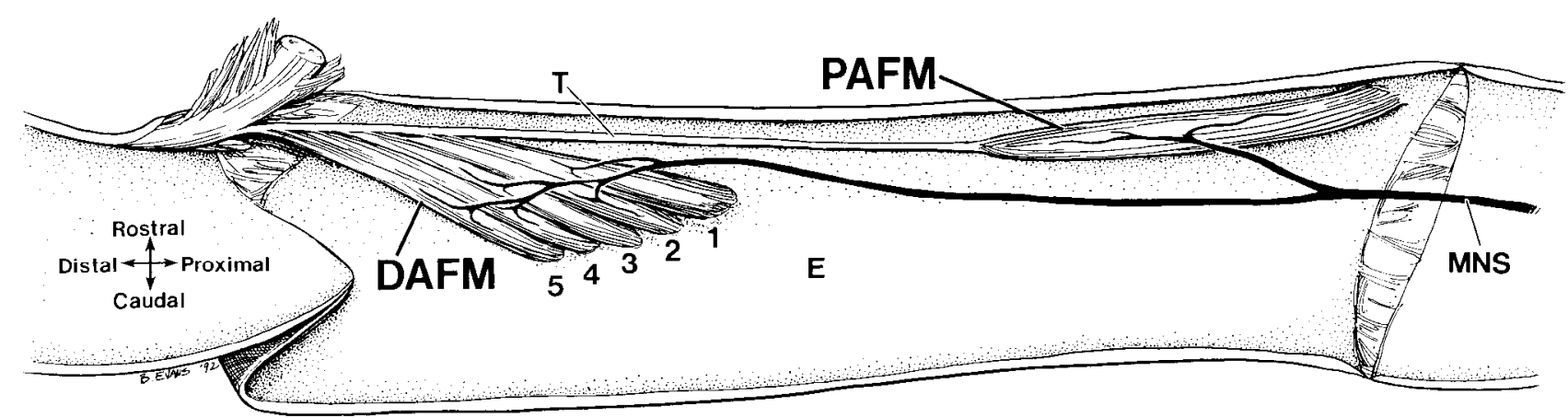

Figure 1. Diagram of the Accessory Flexor Muscle in the lobster walking leg. Overlying exoskeleton and muscles have been removed to expose the proximal (PAFM) and distal (DAFM) divisions of the muscle. Muscle fibers in both divisions extend between a common tendon (T) and the exoskeleton (E). One excitatory and one inhibitory motor neuron (MNS) innervate both divisions. The DAFM is subdivided into 5 muscle fiber bundles, one proximal (1), three medial (2-4), and one distal (5). Transmitter release is regionally differentiated in the DAFM; the excitor and inhibitor both release more transmitter onto the most distal bundle than onto the most proximal bundle. Figure drawn nearly to scale. Magnification, $5 \times$

than their low-output counterparts on tonic muscle fibers (Walrond and Reese, 1985). Moreover, in the lizard, the organization of the active zones differs between the two types of neuromuscular junctions; at the phasic junctions the active zones consist of two linear arrays of intramembrane particles compared to a single such array at the tonic junctions. In these studies, differences between neuromuscular synapses formed by two types of motor neurons (viz. phasic and tonic) provide evidence that link the amount of transmitter released to the structure of the active zone. These findings have given rise to a structure-function hypothesis that states that the number and distribution of active zone particles at an active zone determines the probability that transmitter will be released at that site (Walrond and Reese, 1985; Atwood and Lnenicka, 1986).

To provide a more compelling test of this structure-function hypothesis, we examined the structure of active zones at synapses that are formed by a single motor neuron, but release different amounts of neurotransmitter. Crustacean muscles are prime candidates for such studies because they are innervated by a small number of motor neurons that are readily identifiable. For example, two motor neurons, one excitatory and one inhibitory, innervate the accessory flexor muscle (Fig. 1). This muscle is located in the thoracic limbs of lobsters (Homarus americanus), and is divided into a proximal and a distal head (Wiersma, 1961). The distal head (distal accessory flexor muscle, DAFM) is further subdivided into five muscle fiber bundles. The branch of the excitor that innervates individual muscle fibers in the most distal bundle of the DAFM generates a larger excitatory postsynaptic potential (epsp) and has a higher quantal output than the branch innervating muscle fibers in the most proximal bundle (Meiss and Govind, 1979). Proximal-distal differences in muscle fiber resting potential and input impedance cannot account for the disparity in epsp amplitude (Meiss and Govind, 1979). Therefore, the branch of the excitor innervating the distal bundle is high-output, and the branch innervating the proximal bundle is low-output. Serial thin-section electron microscopy of individual muscle fibers showed that synapse size was similar for the high- and low-output axon branches, and could not account for the proximal-distal difference in epsp amplitude (Govind and Chiang, 1979; Govind and Meiss, 1979; Govind et al., 1982). In crustaceans, a neuromuscular synapse is defined from thin section views as a single site of close ap- position between the axon terminal and the muscle fiber plasma membrane. For excitatory synapses, these sites are typically less than $1 \mu \mathrm{m}^{2}$.

Although serial thin sections consistently showed a positive correlation between transmitter output and the size of the presynaptic densities, it was impossible to determine the distribution of active zone particles in thin section views. In Manduca, active zones at phasic synapses are only about $10 \%$ longer than their counterparts at tonic synapses, but they contain about $80 \%$ more active zone particles (Rheuben, 1985). Because these differences would not be apparent in thin section studies, it was important to use freeze-fracture techniques to compare active zone structure at high- and low-output synapses in crustaceans. In the present study, the number and distribution of active zone particles were measured in freeze-fracture views of high- and low-output synapses to investigate the relationship of active zone structure to the amount of transmitter released.

In the lobster DAFM, synaptic efficacy is regionally differentiated for both excitatory and inhibitory synapses (Govind and Pearce, 1989). Postsynaptic inhibition, as indicated by inhibitory junctional potentials, was several fold stronger on distal fibers compared to proximal fibers (Walrond et al., 1990). Differences in synapse number appear to be responsible for this proximal-distal difference in inhibitory synaptic efficacy since more inhibitory synapses were found on distal muscle fibers than on their proximal counterparts, and synapse size, active zone length, and active zone number per synapse were similar. However, these conclusions are based on serial thin section studics of rclativcly short regions ( 10 to $20 \mu \mathrm{m}$ ) of muscle fibers. To test the conclusions of the thin section studies more comprehensively, we developed an immunohistochemical technique that uses antibodies directed against the inhibitory neurotransmitter, $\gamma$-amino butyric acid (GABA). Because the majority of synapses are located in swellings in axon terminal branches called varicosities (Jahromi and Atwood, 1974; Florey and Cahill, 1982; Walrond et al., 1990), the distribution of inhibitory synapses along the entire length of a muscle fiber bundle could be estimated in light microscopic views of muscle whole mounts.

Our studies suggest that the structural underpinnings for synaptic efficacy vary for the two axons innervating the lobster DAFM; differences in active zone structure provide the basis for regulating the release of excitatory transmitter while differ- 
ences in synapse number govern the output of the inhibitor. Preliminary results have been presented in abstract form (Walrond and Govind, 1987; Huestis et al., 1989).

\section{Materials and Methods}

\section{Freeze-fracture electron microscopy}

The first or second walking leg was removed from 300-400 gram lobsters (Homarus americanus), the overlying exoskeleton of the meropodite was removed in oxygenated lobster physiological saline $\{472 \mathrm{mM} \mathrm{NaCl}$, $10 \mathrm{~mm} \mathrm{KCl}, 16 \mathrm{~mm} \mathrm{CaCl}_{2}, 7 \mathrm{~mm} \mathrm{MgCl}_{2} 6 \mathrm{H}_{2} \mathrm{O}, 10 \mathrm{~mm}$ glucose, $10 \mathrm{~mm}$ Hepes, ( $\mathrm{N}$-[2-hydroxyethyl] piperazine- $\mathrm{N}^{\prime}$-[2-ethanesulfonic acid]), $\mathrm{pH}$ 7.4) to expose the distal accessory flexor muscle, and fixed ( $3 \%$ glutaraldehyde and $1 \%$ paraformaldehyde in lobster physiological saline) in situ at room temperature. Aldehyde-fixed muscles were glycerinated through a graded series to $25 \%$ glycerol in water and removed from their attachment to the exoskeleton. The most distal and proximal muscle fiber bundles were separated from the remainder of the muscle, sandwiched between two gold specimen carriers, and frozen in Freon slush cooled with liquid nitrogen. The preparations were fractured with the double replica technique in a Balzers freeze-fracture device, shadowed with a $2 \mathrm{~nm}$ layer of platinum-carbon and backed with $15 \mathrm{~nm}$ of carbon for support.

Morphometric analysis of freeze fracture views. The areas of presynaptic plateaus and postsynaptic plaques were measured in low magnification electron micrographs $(33,000 \times)$ on a digitizing tablet connected to a MacIntosh IIX computer equipped with Image 1.43 software from $\mathrm{NIH}$. The number of active zones in each plateau was also counted on these electron micrographs. High magnification electron micrographs $(250,000 \times)$ were used to count the number of intramembranc particles per active zone. The perimeter of each active zone was traced on a digitizing tablet; active zone areas and major and minor axes were calculated by the software. Computer measurements were compared to sample measurements taken by hand to ensure accuracy. Active zone particle densities were determined for each active zone by counting the number of particles and dividing this number by the area containing these particles. Densities were then normalized to particle number per $10,000 \mathrm{~nm}^{2}$. The density of intramembrane particles in the postsynaptic membrane was determined by counting the number of particles within a known area.

\section{Thin section electron microscopy}

Walking legs were removed from the animals and dissected as described above. The preparation was fixed for electron microscopy $(2.5 \% \mathrm{glu}$ taraldehyde, $0.5 \%$ formaldehyde, $4 \%$ sucrose, and $0.1 \% \mathrm{CaCl}_{2}$ in $0.1 \mathrm{M}$ sodium cacodylate buffer, $\mathrm{pH} 7.4$ ) in situ for $45 \mathrm{~min}$ (Pearce et al., 1986). The most proximal and distal muscle fiber bundles were separated from the muscle, fixed for an additional $1 \mathrm{hr}$, rinsed $(30 \mathrm{~min})$ in fixative-free buffer, osmicated for $\mathrm{I} \mathrm{hr}$ in buffered $2 \% \mathrm{OsO}_{4}$, rinsed briefly in cacodylate buffer, dehydrated through a graded series of ethanol, cleared in propylene oxide, and embedded in Epon-araldite.

Muscle fiber bundles were sectioned (70-80 nin thick), mounled on formvar-coated single slot grids, stained with aqueous uranyl acetate and lead citrate and examined in a Zeiss $9 S$ electron microscope. To determine synapse size and dense bar lengths, a record was kept of the thickness of each section based on interference colors (Peachey, 1958).

Analysis of thin sections. Muscle fiber circumferences and areas were measured in low magnification views $(750 \times)$ at three stations along the length of the muscle fibers and averaged. Measurements of muscle fiber bundle cross sectional areas and circumferences were made on a digitizing tablet connected to a MacIntosh IIX computer equipped with Image 1.43 software from NIH. Measurements from three sites along the length of each of the fiber bundles were averaged to obtain cross sectional areas and circumferences.

\section{GABA immunohistochemistry}

Methods for whole mount staining of neurons for the neurotransmitter $\gamma$-amino butyric acid (GABA) were modified from Johnson and Stretton (1987). The DAFM was dissected as described above from animals weighing between 100 and 200 grams, fixed in $3 \%$ glutaraldehyde in Phosphate Buffered Saline (PBS: 0.1 m phosphate buffer, $0.3 \mathrm{M} \mathrm{NaCl}$, $\mathrm{pH} \mathrm{7.4)} \mathrm{for} 30 \mathrm{~min}$ at room temperature, rinsed in PBS, and removed from the exoskeleton. The most distal and proximal muscle fiber bundles were incubated in $1 \%$ ethanolamine for $30 \mathrm{~min}$, rinsed in PBS for 10 $\mathrm{min}$, incubated in protease $(1 \mathrm{mg} / \mathrm{ml}$ in PBS) for $30 \mathrm{~min}$, rinsed for 10 $\mathrm{min}$ in PBS and transferred to Tris-buffered saline [TBS: $0.1 \mathrm{M}$ Tris (Tris[hydroxymethyl]aminomethane), $0.3 \mathrm{M} \mathrm{NaCl}, 1 \mathrm{mg} / \mathrm{ml}$ bovine serum albumin, $0.05 \%$ Triton $\mathrm{X}-100, \mathrm{pH} 7.4$ for $10 \mathrm{~min}$ followed by a 10 min rinse in $\mathrm{TBS}^{+}$(TBS containing $10 \%$ fetal calf serum and $0.5 \%$ Triton X-100). Muscle fiber bundles were incubated in $15 \mu \mathrm{g} / \mathrm{ml}$ normal goat serum on a shaker at $8^{\circ} \mathrm{C}$ overnight, rinsed 6-8 times ( $10 \mathrm{~min}$ each) in TBS, and incubated in rabbit anti-GABA (Chemicon International) in $\mathrm{TBS}^{+}$overnight, rinsed as before in TBS, incubated in biotinylated goat anti-rabbit antibody in $\mathrm{TBS}^{+}$overnight on a shaker at $8^{\circ} \mathrm{C}$, rinsed as before in TBS, incubated with horseradish peroxidase coupled to biotin-avidin (Vectastain ABC kit, Vector Laboratories) in TBS overnight, rinsed 6 times ( $10 \mathrm{~min}$ each) in TBS and twice $(10 \mathrm{~min}$ each) in PBS, developed with 4, 4' -diaminobenzidine (DAB) and $\mathrm{H}_{2} \mathrm{O}_{2}$ for 10 15 min, rinsed 4 times in PBS, dehydrated through a graded ethanol series, transferred to xylene, and mounted between two coverslips in Permount.

Analysis of inhibitory innervation. Proximal and distal muscle fiber bundles from the same animal were selected for analysis based on several criteria: a) the density of the $\mathrm{DAB}, \mathrm{H}_{2} \mathrm{O}_{2}$ reaction product was dark and evenly distributed in all axon terminal varicosities on the two muscle fibcr bundles, $b$ ) the staining was uniform in axon terminals along the length of the muscle fibers, c) varicosities were observed on both sides of each muscle fiber, and d) at least 3 muscle fibers in each bundle that met criteria $a-c$ could be traced along the entire length of the bundle. To map the innervation in these preparations, video images of each muscle fiber bundle were digitized and printed. Measurements of muscle fiber diameter, muscle fiber length, varicosity size, varicosity number, and varicosity number per length of axon terminal, were made with a calibrated eyepiece on a light microscope and scored on the printout of the digitized images. Varicosity areas were digitized directly from the computer screen. To compare varicosity densities on fibers of different widths and lengths, the number of varicosities was normalized to a unit area of muscle fiber surface. The diameter of the fiber may vary along its length because muscle fibers frequently bifurcate and fuse with neighboring fibers. To compensate for these variations, muscle fiber diameters were measured at several points along the length of the muscle, and the fiber surface area was calculated from a mean diameter by assuming a cylinder $(A=\pi \mathrm{dl})$. Because fiber surface area and diameter are proportional, changes in fiber diameter are directly related to surface area. For example, a $100 \mu \mathrm{m}$ diameter fiber would have the same surface area as two $50 \mu \mathrm{m}$ diameter fibers of the same length. To estimate the varicosity density, the number of varicosities on the fiber was divided by the fiber surface area.

Controls for GABA antibody binding. Three muscles were processed simultaneously for the control studies. The positive control was processed as described above. In the second muscle, the staining procedure was carried out as described except that the primary antibody (antiGABA) was omitted. In the third muscle, the primary antibody was prcabsorbed with a GABA-BSA-glutaraldehyde conjugate. The conjugate was formed by adding glutaraldehyde to a final concentration of $1 \%$ in PBS containing $5 \mathrm{~mm}$ GABA and $5 \mathrm{mg} / \mathrm{ml} \mathrm{BSA}$, stirring at room temperature for $\mathrm{l} \mathrm{hr}$, and dialyzing against 10 volumes of PBS overnight (Johnson and Stretton, 1987; McDonald et al., 1989).

\section{Results}

\section{Characterization of excitatory and inhibitory innervation}

The characteristic organization of the postsynaptic membranes at excitatory and inhibitory synapses provides a criterion for distinguishing these two types of synapses in freeze-fracture views. At excitatory synapses, intramembrane particles are tightly packed in circular or oval plaques in the sarcolemmal E-face of the postsynaptic membrane (Figs. 2, 4, 5, and 7). At inhibitory synapses, the intramembrane particles in the postsynaptic membrane are organized in parallel rows that extend for long distances in the sarcolemmal P-face (Franzini-Armstrong, 1976; Pearce et al., 1986; Walrond et al., 1990). Active zones at excitatory synapses are confined to circular or oval elevations (plateaus) in the excitatory axon terminal P-face (Figs. 2, 3, 5, and 6). In contrast, active zones in the inhibitor are not found on plateaus and are widely distributed (Walrond et al., 1990). 

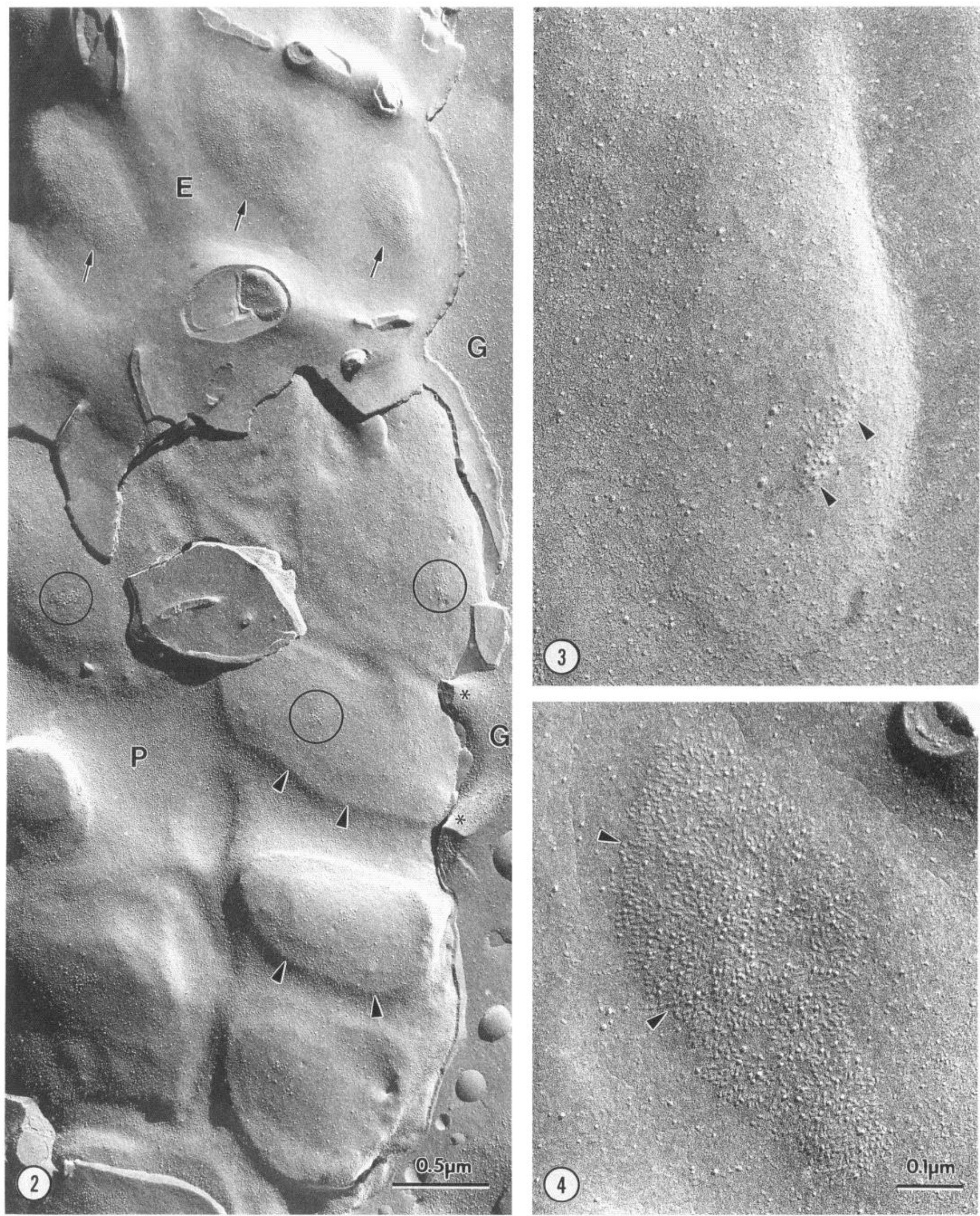

Figure 2. Freeze-fracture view of a high-output, excitatory motor axon terminal on the most distal muscle fiber bundle in the DAFM. Synapses (arrowheads) are recognized as raised plateaus in the axon terminal protoplasmic leaflet (P). Each synapse contains one or more active zones (circles). 
Table 1. Comparison of excitatory synapse dimensions from freeze-fracture

\begin{tabular}{|c|c|c|}
\hline & $\begin{array}{l}\text { Distal } \\
\text { (high output) }\end{array}$ & $\begin{array}{l}\text { Proximal } \\
\text { (low output) }\end{array}$ \\
\hline \multicolumn{3}{|l|}{ Presynaptic } \\
\hline Area per synapse $\left(\mu \mathrm{m}^{2}\right)^{a}$ & $\begin{array}{l}0.71 \pm 0.05^{b} \\
(n=46)\end{array}$ & $\begin{array}{l}0.64 \pm 0.05 \\
(n=31)\end{array}$ \\
\hline \multicolumn{3}{|l|}{ Postsynaptic } \\
\hline Plaque area $\left(\mu \mathrm{m}^{2}\right)^{a}$ & $\begin{array}{l}0.22 \pm 0.01 \\
(n=55)\end{array}$ & $\begin{array}{l}0.28 \pm 0.07 \\
(n=15)\end{array}$ \\
\hline E-face particles per $\mu \mathrm{m}^{2}$ of synapse & $\begin{array}{l}3631 \pm 349 \\
(n=6)\end{array}$ & $\begin{array}{l}3741 \pm 262 \\
(n=6)\end{array}$ \\
\hline
\end{tabular}

Based on these criteria, most of the axon terminals observed in the present study were excitatory; the few inhibitory terminals that were obscrved were confined to the distal bundle. These findings are in agreement with previous serial thin-section studies that suggested that the inhibitor forms fewer synapses than the excitor (Govind and Pearce, 1989; Walrond et al., 1990).

\section{Excitatory innervation of proximal and distal bundles}

Synaptic structure. To examine the hypothesis that the regional differences in transmitter release result from differences in synapse structure, freeze-fracture views of excitatory synapses were obtained in proximal and distal muscle fiber bundles from 4 animals. These views showed qualitatively similar synaptic contacts in the two muscle fiber bundles (Figs. 2 and 5). Morphometric analysis of the presynaptic plateau areas showed no significant difference between synapse size on the two muscle fiber bundles (Table 1). Nearly all of the plateaus had at least one presynaptic active zone that was recognized as a cluster of large intramembrane particles in the axolemmal P-face (Figs. 3 and 6). A single active zone was found on $48 \%$ of the proximal (low output) synapses and on $62 \%$ of the distal (high-output) synapses. Multiple active zones were found on $48 \%$ of the proximal synapses and on $38 \%$ of the distal synapses (Fig. 8). Therefore, proximal-distal differences in the number of transmitter release sites per synapse cannot account for the larger epsp's seen on distal muscle fibers by Meiss and Govind (1979).

Differences in the number of receptors available to bind excitatory transmitter and open ligand-gated channels might contribute to proximal-distal differences in epsp amplitude. Tightly packed E-face particles organized in circular or oval patches (plaques) in the postsynaptic membrane are characteristic of excitatory neuromuscular synapses in arthropods (FranziniArmstrong, 1976; Rheuben and Reese, 1978; Rheuben, 1985). If, as these authors suggest, the particles represent glutamate receptor-ion channel complexes, the density of the particles in the plaques could provide an indication of the density of glutamate receptors at proximal and distal synapscs (Figs. 4 and 7). The density of E-face particles was similar at synapses on the two muscle fiber bundles (Table 1). Plaque size was also similar at high- and low-output synapses (Table 1), and a median test indicated that there is no proximal-distal difference in the distribution of plaque sizes.

Although receptor availability does not appear to contribute to the proximal-distal disparity in epsp amplitude, variations in receptor availability could affect the amplitude of unitary quantal events. Plaque areas from the two muscle fiber bundles were plotted as a frequency histogram (Fig. 9). Plaque size ranged from 0.03 to $0.92 \mu \mathrm{m}^{2}$, and $87 \%$ of the plaques were between 0.05 and $0.35 \mu \mathrm{m}^{2}$. Because the particle density in the plaques is about 3700 per $\mu \mathrm{m}^{2}$ (Table 1), a typical plaque would contain more than 700 putative receptor-ion channel complexes, and the smallest plaque would contain about 100 .

Taken together, these results suggest that proximal-distal differences in the efficacy of excitatory synaptic transmission in the DAFM are not due to differences in the size of the presynaptic plateaus, the number of transmitter release sites per synapse, or the availability of postsynaptic receptor sites per synapse. To test the hypothesis that differences in the total number of synapses per muscle fiber could account for the disparity in epsp amplitude, synaptic density was estimated with thin section electron microscopy by sampling long $(5 \mathrm{~mm}$ ) lengths of proximal and distal fiber bundles from a single muscle. Samples were taken at approximately $50 \mu \mathrm{m}$ intervals at 91 stations in the proximal bundle and at 92 stations in the distal bundle. There were 182 and 272 synapses recorded in the proximal and distal bundles respectively. Because the proximal bundle was smaller than the distal bundle (199 vs. $245 \mu$ m diameter), the synapse number was normalized to the perimeter of muscle fiber mem-

\footnotetext{
Postsynaptic membranes contain plaques (arrows) of large intramembrane particles and lie in shallow depressions in the sarcolemmal E-face (E). A glial cell $(G)$ lies adjacent to the neuromuscular junction and interdigitates between the plateaus (*). Magnification, 37,000 $\times$.

Figure 3. High magnification view of a high-output excitatory synapse. Active zones are recognized as linear arrays of large intramembrane particles (arrowheads) in the axon terminal protoplasmic leaflet. The arrays correspond in size and position to the presynaptic densities seen in thin sections. Magnification, 100,000x.

Figure 4. Enlargement of a postsynaptic, E-face plaque from Figure 2. The intramembrane particles, presumably glutamate receptor-ion channel complexes, are arranged in circular or oval plaques in the sarcolemmal E-face (arrowheads). The postsynaptic plaques are smaller than the presynaptic plateaus. Magnification, $100,000 \times$.
} 

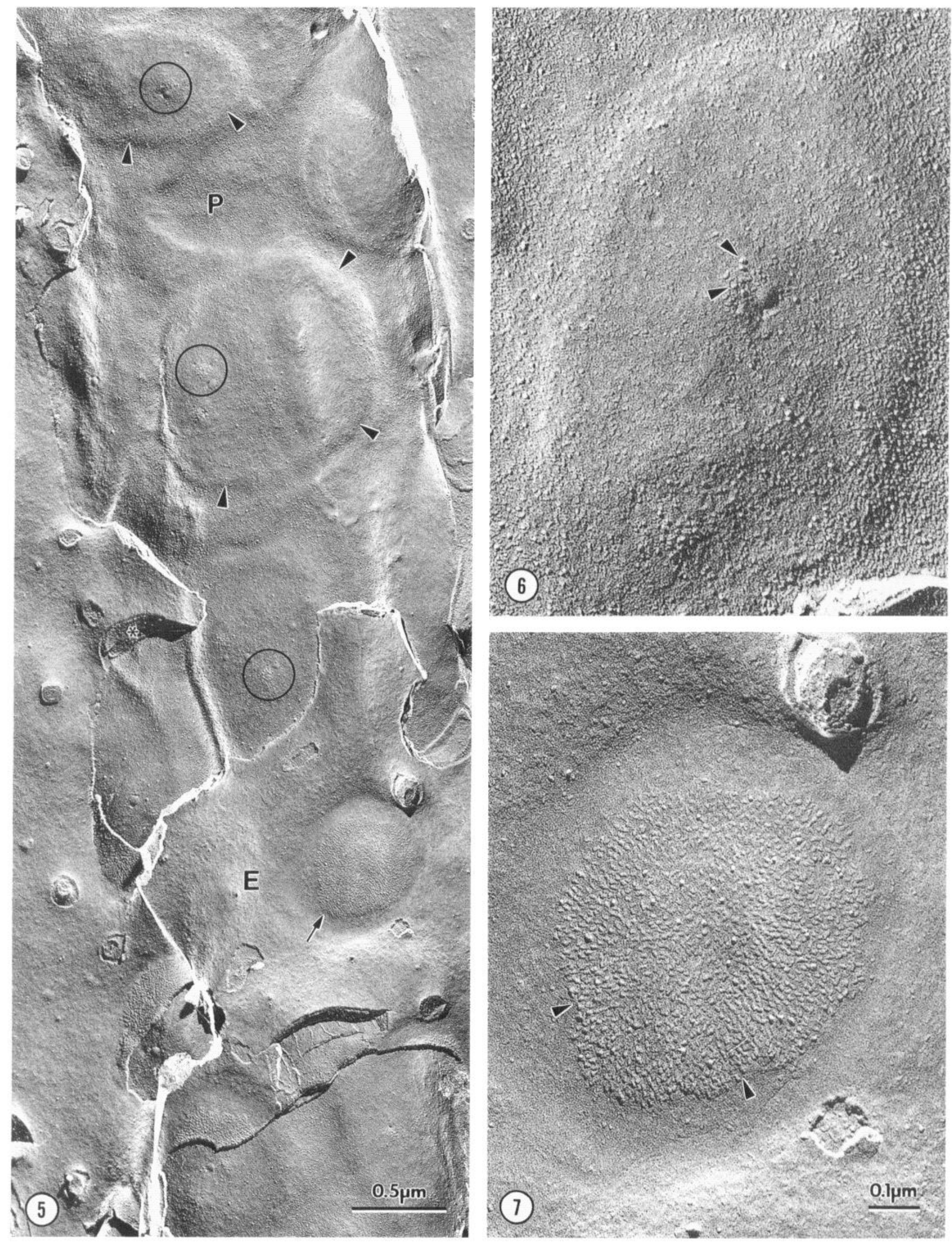


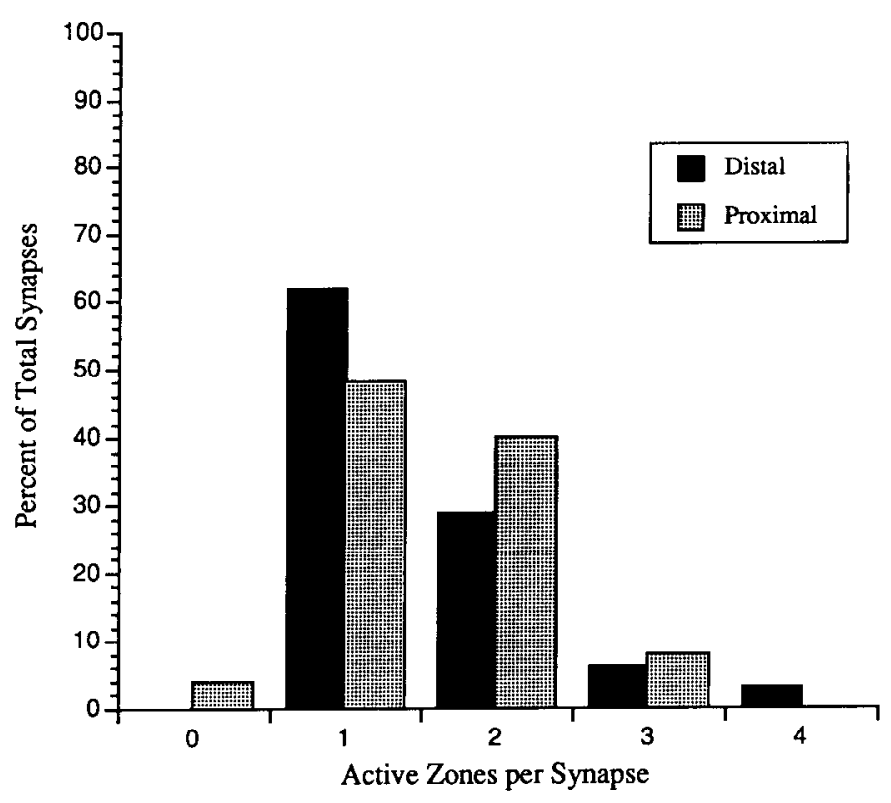

Figure 8. Frequency histogram of active zones per synapse at highand low-output synapses in the DAFM. The number of active zones per synapse was similar in axon terminals on the most distal and on the most proximal muscle fiber bundles since a chi square test showed that the distributions were not significantly different $(p>0.20)$. All of the synapses on the most distal bundle $(n=76)$ contained at least onc active zone, and about $91 \%$ of the synapses contained one or two active zones. On the most proximal muscle fiber bundle, about $88 \%$ of the synapses $(n=48)$ contain one or two active zones and about $5 \%$ contained no active zones.

brane available for synaptic contacts. For proximal and distal bundles respectively, this normalization yielded a value of 85 and 93 synapses per $\mathrm{mm}$, and indicated that differences in synapse number cannot account for the nearly 10 fold proximaldistal disparity in epsp amplitude (Meiss and Govind, 1979).

Active zone structure. Freeze-fracture views of synapses on high- and low-output axon branches showed that differences in active zone structure are indicative of regional differences in the amount of excitatory transmitter released. At high-output synapses on the most distal muscle fiber bundle, active zones contain more active zone particles than at low-output synapses on the most proximal muscle fiber bundle (Figs. 3, 6, and 10). Active zones at low-output synapses contained an average of 14 active zone particles compared to an average of 21 at highoutput synapses (Table 2). Because these larger active zones are both wider and longer, they cover an area about $58 \%$ larger than their low-output counterparts (Table 2). However, the density of active zone particles is nearly identical regardless of the active zone size (Table 2). Although the distributions of active zone particle number per active zone overlap, large active zones are

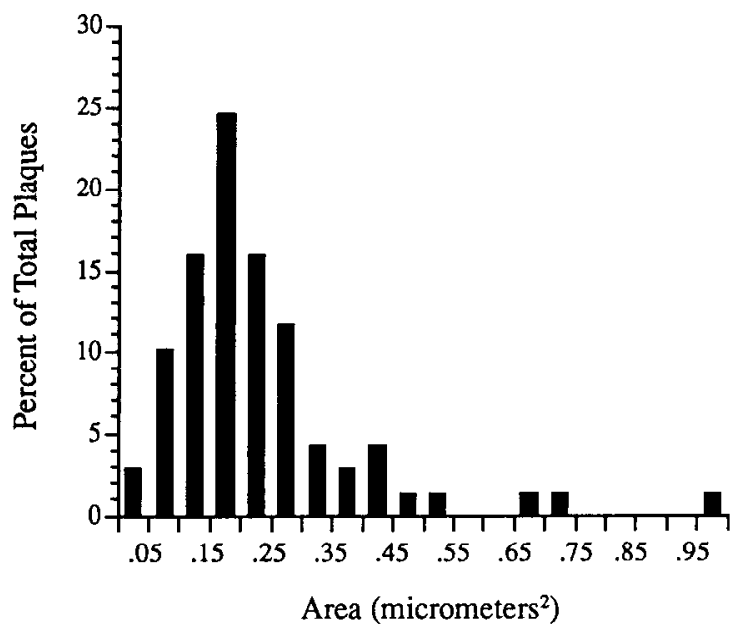

Figure 9. Frequency histogram of postsynaptic plaque areas. Most of the plaque areas were distributed around a mean of $0.20 \mu \mathrm{m}^{2}$. Because proximal-distal differences in plaque areas were not significantly different when tested by either a median test or a $t$-test, areas from 15 proximal and 55 distal plaques were combined $(n=70)$.

more common at synapses on the most distal muscle fiber bundle. Only $13 \%$ of the active zones on the proximal muscle fiber bundle contain 18 or more particles, yet $60 \%$ of the active zones at synapses on the distal muscle fiber bundle contain at least 18 particles (Fig. 10).

\section{Inhibitory innervation of proximal and distal bundles}

Serial thin section studies through short regions of individual muscle fibers found more excitatory synapses than inhibitory synapses on both the proximal and distal bundles. However, inhibitory synapses were encountered more frequently distally than proximally (Govind and Pearce, 1989; Walrond et al., 1990). If this asymmetry in the distribution of inhibitory synapses would extend for the length of the muscle fiber bundles, it could account for the proximal-distal difference in inhibitory synaptic efficacy (Walrond et al., 1990). To test this assumption, we traced the pattern of inhibitory innervation in whole mounts of proximal and distal muscle fiber bundles using antibodies to the inhibitory neurotransmitter, GABA. Antibodies specific to GABA were localized to the inhibitory motor neuron, and the DAB reaction product was evenly distributed throughout the inhibitory motor neuron (Figs. 11 and 12).

The antibodies were specific for the inhibitory motor neuron since the $\mathrm{DAB}$ reaction product was always confined to a singlc motor neuron in each preparation (Figs. 11-13). Control studies were performed to determine if the primary antiserum was specific for a GABA-like epitope in the lobster DAFM. The positive control, which was run in parallel with the other staining con-

$\longleftarrow$

Figure 5. Freeze-fracture view of a low-output, excitatory motor axon terminal on the most proximal muscle fiber bundle in the DAFM. One or more active zones (circles) are located on each synapse which is recognized as a plateau (arrowheads) in the axon terminal protoplasmic leaflet (P). Postsynaptic membranes in the external leaflet of the sarcolemma (E) contain circular or oval plaques (arrows) of large intramembrane particles confined to shallow depressions. A glial cell process $\left(^{*}\right)$ interdigitates between synapses. Magnification, $37,000 \times$.

Figure 6. Enlargement of a presynaptic plateau from Figure 5. Active zones are recognized as clusters of large intramembrane particles (arrowheads) in the axon terminal P-face. Active zones formed by the low-output branch of the excitor generally contain fewer intramembrane particles than their counterparts on the high-output branch. Magnification, 100,000 $\times$.

Figure 7. Enlargement of a postsynaptic membrane from Figure 5. Large intramembrane particles are arranged in circular or oval plaques (arrowheads) in the sarcolemmal E-face. Plaque size and particle density within the plaque was similar for synapses on the most proximal and distal muscle fiber bundles. Magnification, 100,000×. 


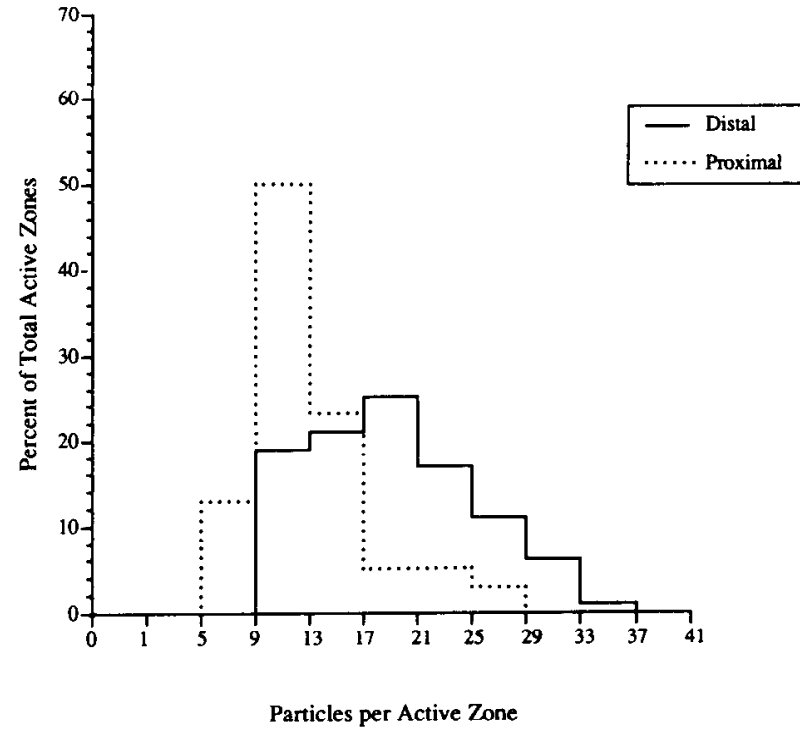

Figure 10. Frequency histogram of active zone particle number on the proximal and distal muscle fiber bundles. Active zones at synapses on the distal bundle contained about $50 \%$ more intramembrane particles than their counterparts on the proximal bundle. Active zones on the high-output branch of the excitor contained $21 \pm 6$ (SD) active zone particles per active zone $(\mathrm{n}=109)$. Active zones on the low-output branch of the excitor contained $14 \pm 4(\mathrm{SD})$ active zone particles per active zone $(n=60)$.

trols, showed a pattern of staining similar to the experimental preparations (Fig. 13). No staining was found in preparations where the GABA antiserum was omitted from the staining procedure (Fig. 14). The specificity of the antiserum was further tested by preincubating the serum in a solution containing GABA conjugated to BSA with glutaraldehyde (Johnson and Stretton, 1987; McDonald et al., 1989). This preincubation completely blocked staining (Fig. 15). The immunohistochemical studies demonstrate that the stained neuron is indeed the inhibitory motor neuron that innervates the DAFM since GABA is well established as the inhibitory transmitter in crustaceans (Otsuka et al., 1966).

Proximal-distal differences in the distribution of inhibitory synapses could be estimated in preparations stained with antibodies to GABA because the antibody-specific reaction product filled axonal swellings where most of the synapses are located (e.g., Jahromi and Atwood, 1974; Florey and Cahill, 1982; Walrond et al., 1990). The inhibitory motor neuron arborizes on the surface of the muscle fibers, and forms varicosities on its higher order axon branches (Figs. 11 and 12). To determine the distribution and density of varicosities, the branching pattern of the inhibitor was traced in light micrographs of the distal and proximal muscle fiber bundles (Fig. 16). Each $100 \mu \mathrm{m}$ length of inhibitory axon terminal in both muscle fiber bundles contained about 15 varicosities (Figs. 11 and 12, Table 3). Varicosity shape and size was also similar in the two bundles; each varicosity covered about $5 \mu \mathrm{m}^{2}$ of muscle fiber surface (Table 3 ).

To compare the density of varicosities on the most proximal and distal muscle fiber bundles, the number of varicosities was normalized to muscle fiber area by measuring the muscle fiber diameter at several sites along the length of each muscle fiber, treating the fiher as a cylinder, and calculating the surface area (see Materials and Methods). In animals weighing between 100 and 200 grams, the density of inhibitory varicosities was about 5 times higher on the distal muscle fiber bundle as on the proximal muscle fiber bundle (Table 3). Varicosity density ranged between 123 and 544 varicosities per $\mathrm{mm}^{2}$ distally and between 18 and 127 varicosities per $\mathrm{mm}^{2}$ proximally. Nearly $80 \%$ of the distal muscle fibers contained more than 180 varicosities per $\mathrm{mm}^{2}$ while none of the proximal muscle fibers contained more than 180 varicosities per $\mathrm{mm}^{2}$ (Fig. 17).

Because the number of active zones per inhibitory synapse was similar on the proximal and distal muscle fiber bundles (Walrond et al., 1990), the proximal-distal difference in varicosity number suggests that there are more active zones available to relcasc transmitter on the high-output branch of the inhibitor than the low-output branch. This conclusion is supported by thin section studies that showed that synapse size, active zone number per synapse, and active zone structure are similar at inhibitory synapses on the distal and proximal muscle fiber bundles (Govind and Pearce, 1989; Walrond et al., 1990). Taken together, these studies indicate that the proximal-distal disparity in the amount of inhibitory transmitter released in the DAFM is related to regional differences in the number of similarly organized active zones.

Table 2. Comparison of excitatory active zone dimensions from freeze-fracture

\begin{tabular}{lcc} 
Active zone parameters & $\begin{array}{l}\text { Distal } \\
\text { (high output) }\end{array}$ & $\begin{array}{c}\text { Proximal } \\
\text { (low output) }\end{array}$ \\
\hline Particle number per cluster $^{a}$ & $21 \pm 0.6^{b}$ & $14 \pm 0.6$ \\
& $(n=109)$ & $72 \pm 2$ \\
Particle cluster width $(\mathrm{nm})^{c}$ & $80 \pm 1$ & $105 \pm 4$ \\
Particle cluster length $(\mathrm{nm})^{a}$ & $150 \pm 5$ & $5875 \pm 142$ \\
Particle cluster area $\left(\mathrm{nm}^{2}\right)^{a}$ & $9301 \pm 258^{d}$ & $24 \pm 1.5$ \\
Particle density in cluster (per 10,000 $\left.\mathrm{nm}^{2}\right)$ & $24 \pm 0.60$ & $(n=28)$
\end{tabular}

The proximal-distal disparity in the amount of excitatory transmitter released correlates with proximal-distal differences in active zone structure.

"Measurements are significantly different $(p<0.0001)$.

'SEM, except where noted.

Measurements are significantly different $(p<0.001)$.

"SD. 

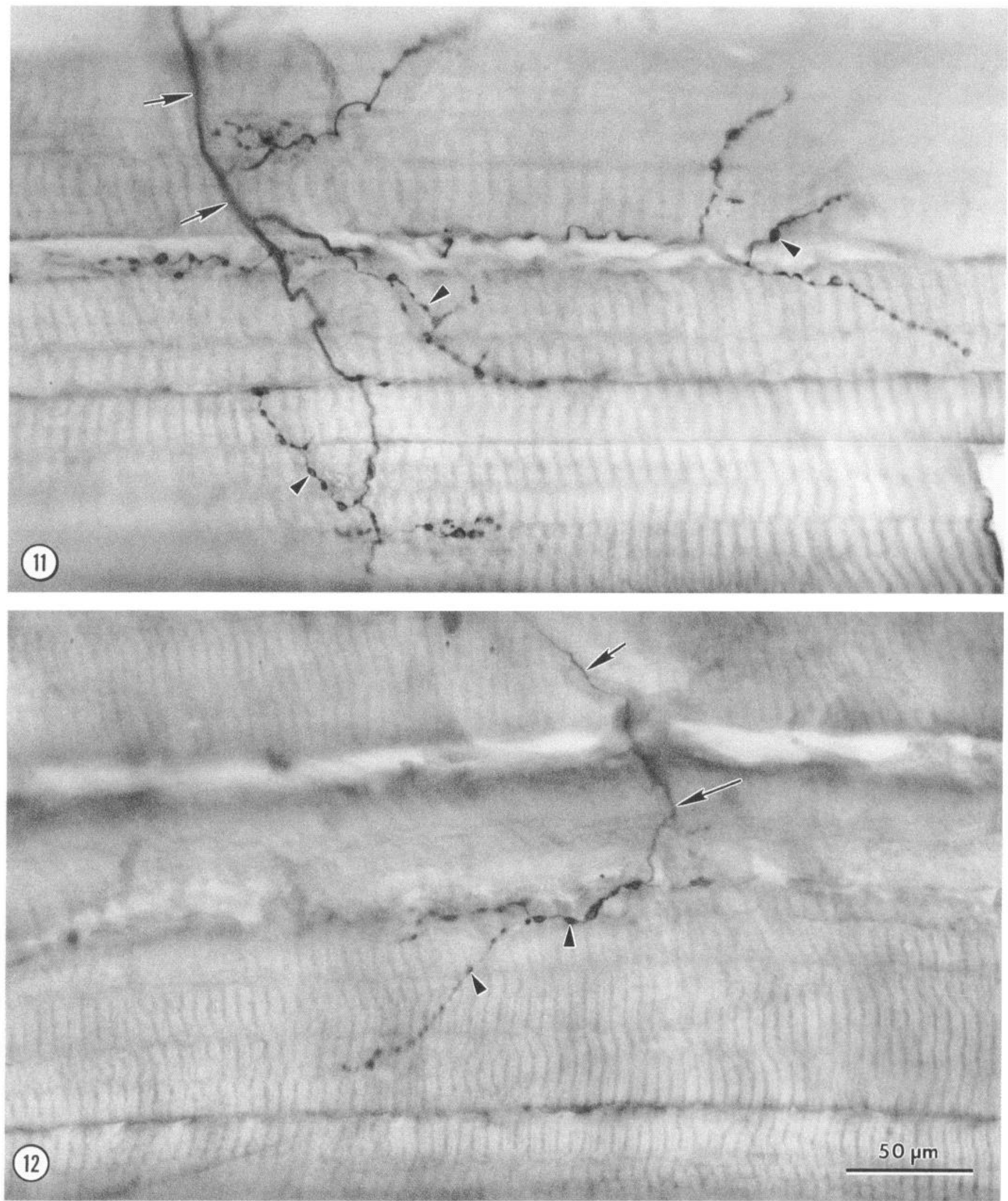

Figure 11. Light micrograph of the inhibitory motor neuron on a distal muscle fiber bundle. The inhibitor was stained for an antibody to the inhibitory neurotransmitter, GABA, and viewed in whole mounts of the muscle fiber bundle. The diaminobenzidine/horseradish peroxidase reaction product outlines the motor axon (arrows) as it branches and forms varicosities (arrowheads) on the surface of the muscle fibers. Inhibitory synapses are located predominately in the varicosities. Magnification, $465 \times$.

Figure 12. Light micrograph of the inhibitory motor neuron on a proximal muscle fiber bundle which has been stained for an antibody to GABA and viewed as a whole mount. The axon (arrows) branches and forms varicosities (arrowheads). Varicosity size and number per length of motor axon terminal are similar on distal and proximal muscle fiber bundles. The inhibitor forms fewer varicosities on the proximal bundle than on the distal bundle. Magnification, $465 \times$. 

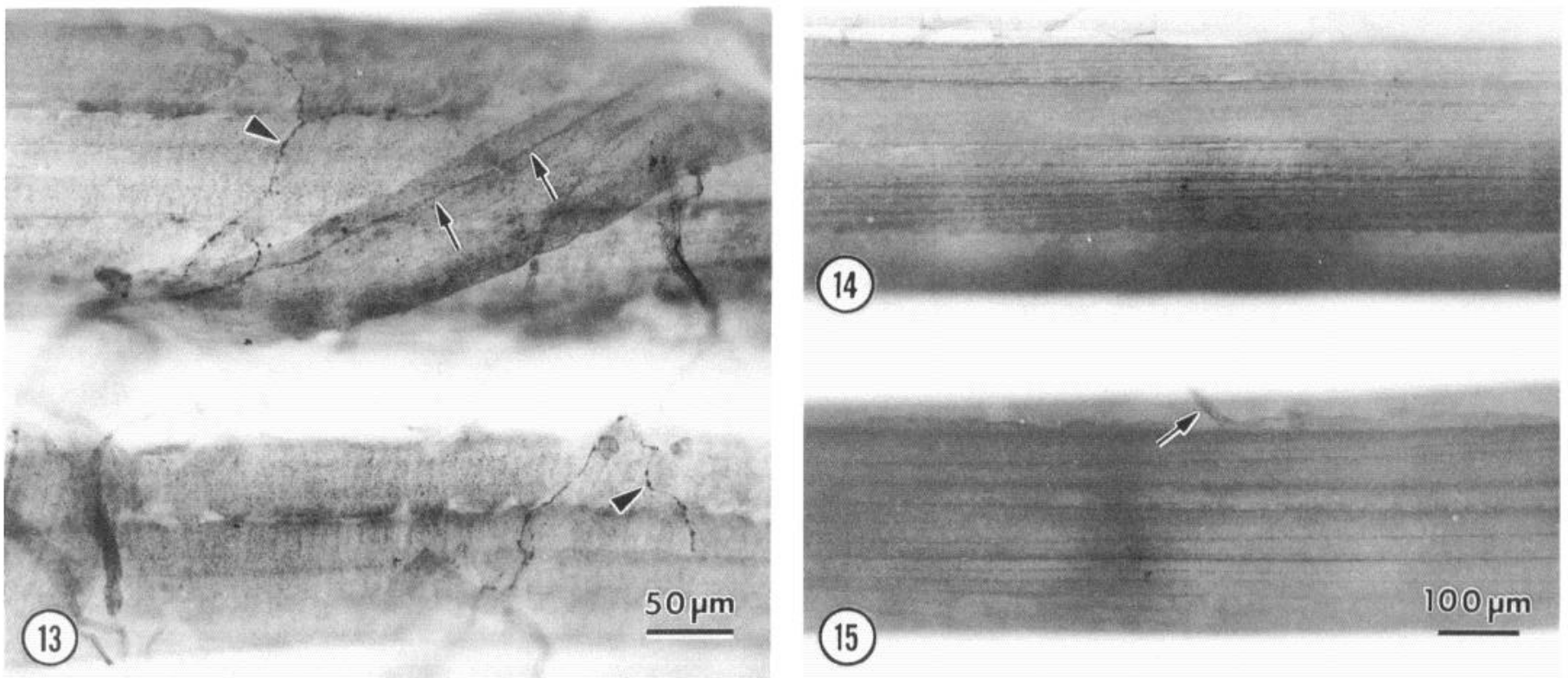

Figure 13. Whole mount view of a positive control. Light micrograph of the inhibitory motor neuron on a distal muscle fiber bundle stained for an antibody to GABA that was processed in parallel with negative control preparations in Figures 14 and 15 . The inhibitor runs in the main nerve (arrows) and forms varicosities on the muscle surface (arrowheads). Magnification $\times 220$.

Figure 14. Whole mount view of a distal muscle fiber bundle processed without primary antibody. No staining was observed in preparations in which the primary antibody was omitted. The length of the bundle shown is about one mm and represents about $25 \%$ of the bundle in adult animals. Magnification $95 \times$.

Figure 15. Whole mount view of a distal muscle fiber bundle processed with preabsorbed primary serum. No staining was observed in the nerve (arrow) or on the muscle fiber surface when the primary antibody was preabsorbed with a GABA-BSA-glutaraldehyde conjugate before addition of primary serum. Magnification $95 \times$.

\section{Discussion}

Structural adaptations regulating excitatory transmitter release The present study uses freeze-fracture and thin section electron microscopy of excitatory synapses in the DAFM to study the relationship of synapse structure and synaptic efficacy. The freeze- fracture studies show that synapse size, and active zone number per synapse is similar for synapses on the proximal and distal muscle fiber bundles. Thin sections cut at intervals along the length of the two bundles indicate that differences in the number of excitatory synapses are not sufficient to account for the proximal-distal disparity in epsp amplitude, which may approach

Table 3. Characteristics of inhibitor varicosities from whole-mounts

\begin{tabular}{lcc} 
& $\begin{array}{l}\text { Distal } \\
\text { (high output) }\end{array}$ & $\begin{array}{l}\text { Proximal } \\
\text { (low output) }\end{array}$ \\
\hline $\begin{array}{l}\text { Number of animals } \\
\text { Number of muscle fiber bundles }\end{array}$ & 3 & 3 \\
Number of muscle fibers & 5 & 5 \\
Total number of varicosities & 18 & 15 \\
Varicosity size $(n=85)$ & 4183 & 1518 \\
$\quad$ & $3.0 \pm 0.13^{b}$ & $3.0 \pm 0.14$ \\
$\quad$ Major axis $(\mu \mathrm{m})$ & $1.9 \pm 0.09$ & $1.7 \pm 0.09$ \\
$\quad$ Minor axis $(\mu \mathrm{m})$ & $5.2 \pm 0.44$ & $4.9 \pm 0.45$ \\
$\quad$ Area $\left(\mu \mathrm{m}^{2}\right)$ & $324 \pm 28$ & $63 \pm 9$ \\
Varicosities per mm ${ }^{2}$ of muscle fiber & 5 & 1 \\
Ratio of varicosity density & $14 \pm 4^{c}$ & $15 \pm 4$ \\
Varicosities per $100 \mu \mathrm{m}$ of axon length & $(n=83)$ & $(n=72)^{*}$
\end{tabular}

Varicosities on the distal and proximal muscle fiber bundles are similar in size and frequency along inhibitory axon terminals. The density of inhibitory varicosities is higher on the distal fiber bundle than on the proximal muscle fiber bundle.

- In two animals, varicosities were measured in proximal and distal muscle fiber bundles from two legs.

${ }^{b}$ All errors are expressed as SEM, except where noted.

SSD.

*, The values for $n$ represent measurements taken from lengths of axons ranging from 20 to $500 \mu \mathrm{m}$ and totaling 9.9 $\mathrm{mm}$ proximally and $11.5 \mathrm{~mm}$ distally. Eleven distal and 11 proximal muscle fibers in seven animals were sampled. Measurements were pooled since there was no significant difference among animals. 
10 fold (Meiss and Govind, 1979). Because the number of active zones per synapse was similar on the proximal and distal bundles, proximal-distal differences in the number of transmitter release sites (estimated by multiplying the number of active zones per synapse times the number of synapses) were also insufficient to account for the proximal-distal disparity in quantal content.

The synaptic vesicles located lateral to the dense bar and apposed to the plasma membrane (active zone vesicles) are thought to be the ones that open and release transmitter when $\mathrm{Ca}^{2+}$ enters the terminal at the active zone (Heuser et al., 1974; Heuser et al., 1979; Heuser and Reese, 1981; Govind et al., 1982). Because high-output active zones in the lobster DAFM are about $40 \%$ longer than their low-output counterparts, they can accommodate more synaptic vesicles lined up beside the dense bar, which appears to be coextensive with the active zone particle array (Pearce et al., 1986), and poised to release transmitter (Figs. 3, 6 and 18). In our model, we assumed that a 150 $\mathrm{nm}$ long active zone could accommodate no more than three $50 \mathrm{~nm}$ diameter vesicles on each side of the dense bar (Fig. 18). Similarly, a low-output active zone could accommodate no more than 4 vesicles in this position. Because the number of release sites appears to be similar proximally and distally, this $50 \%$ difference in the number of synaptic vesicles available to open and release transmitter is insufficient to account for the several fold proximal-distal difference in epsp amplitude. These results suggest that, as a population, active zone vesicles in the lowoutput branch have an overall lower probability of opening and releasing transmitter than their counterparts in the high-output branch.

In the lobster DAFM, differences in quantal content correlate with the number of particles per active zone since the density and distribution of active zone particles is similar at high- and low-output synapses (Fig. 18). These results, and earlier studies on lizard synapses (Walrond and Reese, 1985), suggest that the number of particles in an active zone regulates the probability that a depolarization will lead to the fusion of a synaptic vesicle with the axolemma, and release a quantum of transmitter.

Active zone particles as $\mathrm{Ca}^{2+}$ channels. The opening of voltagegated $\mathrm{Ca}^{2+}$ channels in the presynaptic membrane leads to an influx of $\mathrm{Ca}^{2+}$ that couples the action potential to quantal transmitter release. The short delay between $\mathrm{Ca}^{2+}$ influx and transmitter release (Llinás et al., 1981), and the position of the active zone particles adjacent to the release sites has raised speculation that the particles are the $\mathrm{Ca}^{2+}$ channels responsible for transmitter release (Heuser et al., 1974; Pumplin et al., 1981). Recent studies have further strengthened this assertion. In frog motor axon terminals, fluorescently labeled conotoxin, a specific $\mathrm{Ca}^{2+}$ channel blocker, is localized to bands that have the same orientation and spacing as active zones seen in freeze-fracture views (Robitaille et al., 1990; Cohen et al., 1991). The mapping of $\mathrm{Ca}^{2+}$ currents to regions on frog hair cells subsequently identified in freeze-fracture views to contain active zones further suggests that active zone particles may include the $\mathrm{Ca}^{2+}$ channels that couple the action potential to quantal transmitter release (Roberts et al., 1990).

According to some models for transmitter release, the simultaneous opening of several $\mathrm{Ca}^{2+}$ channels in a cluster produces locally high concentrations of intracellular $\mathrm{Ca}^{2+}$ at the transmitter release site (Simon and Llinás, 1985; Walrond and Reese, 1985; Zucker and Fogelson, 1986). Recent experimental evidence consistent with these models indicates that $\mathrm{Ca}^{2+}$ con-

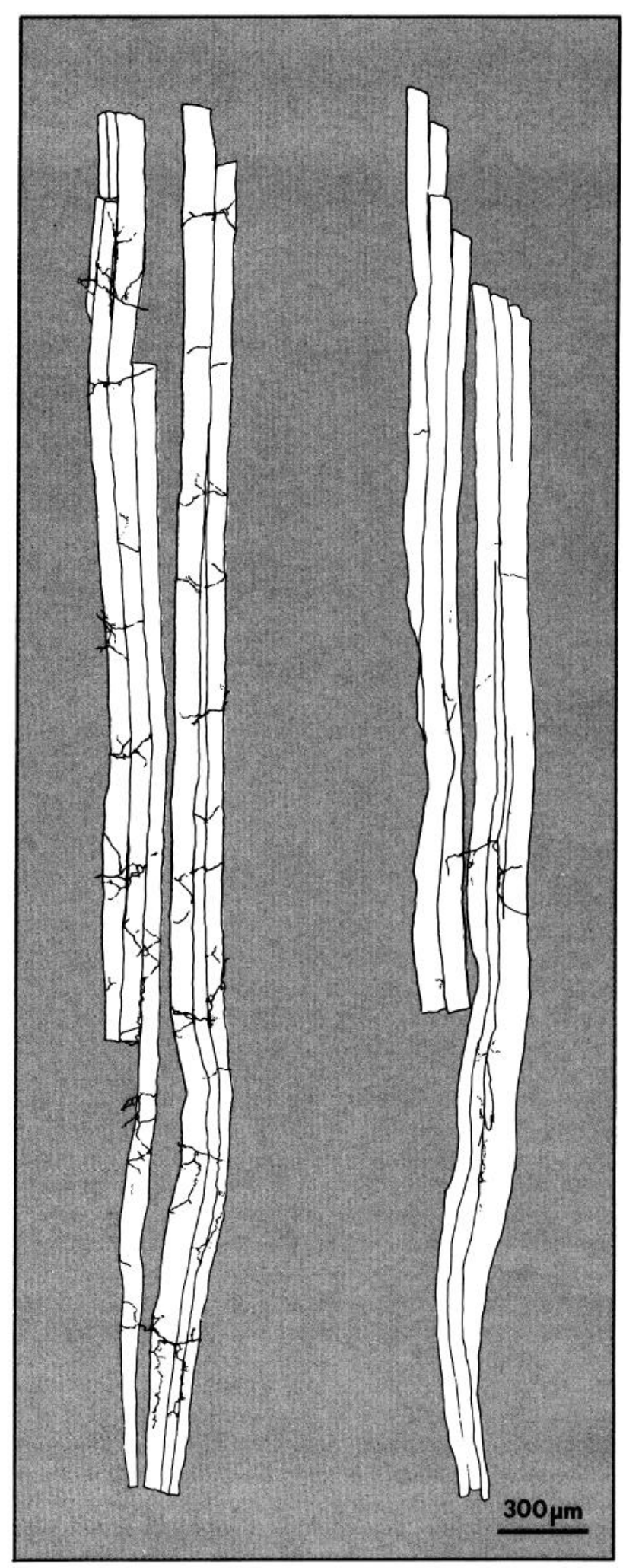

Figure 16. Camera lucida drawing of inhibitory innervation on a distal (left) and proximal (right) muscle fiber bundle from a DAFM in a subadult animal. The pattern of innervation was traced for the entire length of the two bundles; the density of inhibitory innervation is greater on the distal than on the proximal bundle. 


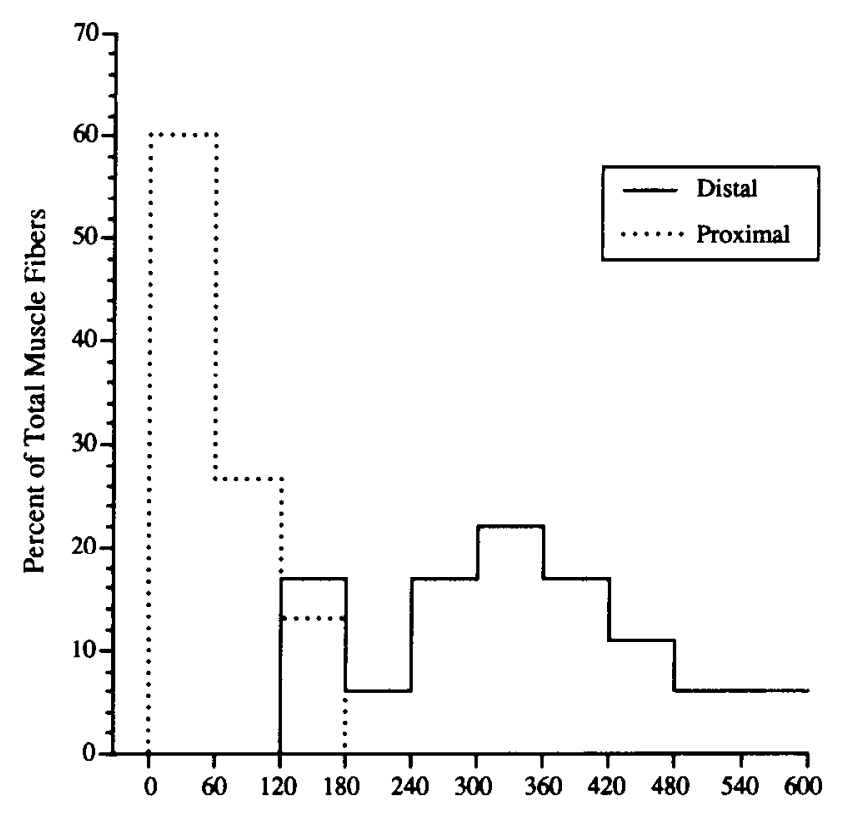

Varicosities per $\mathrm{mm}^{2}$

Figure 17. Frequency histogram of the varicosity density on distal and proximal muscle fiber bundles. The density of varicosities per $\mathrm{mm}^{2}$ of muscle fiber surface area is 5 times greater on the distal muscle fiber bundle than on the proximal bundle in animals weighing 100 to 200 grams. About $13 \%$ of the proximal fibers with the highest varicosity density in this group overlapped with about $15 \%$ of the distal muscle fibers with the lowest varicosity density.

centrations may reach several hundred $\mu \mathrm{M}$ in localized regions in the presynaptic cytoplasm (Roberts et al., 1990; Adler et al., 1991; Llinás et al., 1992). Voltage clamp measurements in the squid giant synapse have estimated a fourth power relationship between $\mathrm{Ca}^{2+}$ current and the amount of transmitter released (Augustine and Charlton, 1986). However, this exponential relationship between $\mathrm{Ca}^{2+}$ and transmitter release is thought to apply only when open $\mathrm{Ca}^{2+}$ channels are located within 100 In of one another and the channels have been open for sufficient time $(2.4 \mathrm{msec})$ so that the domains of high $\mathrm{Ca}^{2+}$ concentrations overlap (Simon and Llinás, 1985; Zucker and Fogelson, 1986; Augustine et al., 1991). For example, doubling the number of open $\mathrm{Ca}^{2+}$ channels with overlapping domains could produce a 16 fold $\left(2^{4}=16\right)$ disparity in the probability of transmitter release assuming a fourth power relationship between intracellular $\mathrm{Ca}^{2+}$ and the probability of release. The disparity may be higher or lower depending on the relationship of the power function to transmitter release (Zucker and Fogelson, 1986). Additionally, if the probability of channel opening is significantly less than one and several overlapping $\mathrm{Ca}^{2+}$ domains are required for transmitter release to become likely, it follows from binomial statistics that increasing the number of channels would increase the probability of transmitter release in a nonlinear fashion (Walrond and Reese, 1985).

There appear to be at least three factors that contribute to the proximal-distal disparity in epsp amplitude which may reach 10 fold in the lobster DAFM (Meiss and Govind, 1979). First, because the input resistance is about $20 \%$ higher in distal muscle fibers than in proximal fibers, releasing the same number of quanta distally and proximally would produce a larger depolarization distally. Second, the high-output active zones are lon-
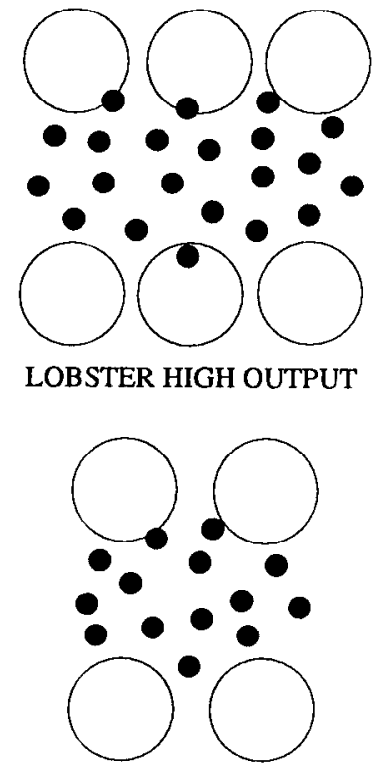

LOBSTER LOW OUTPUT

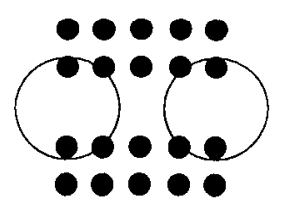

LIZARD TWITCH

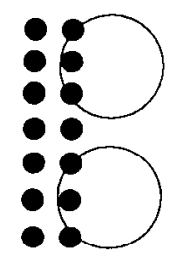

LIZARD TONIC $\overline{20 \mathrm{~nm}}$

Figure 18. Diagram of high- and low-output active zones at excitatory synapses at lobster and lizard neuromuscular junctions. The difference in quantal content at lizard twitch (high-output) and tonic (low-output) active zones correlates with a difference in the number and distribution of active zone particles (small, solid circles). In lobsters, differences in transmitter release correlate with differences in the number of active zone particles which are organized similarly at high- and low-output active zones. Active zone vesicles (large open circles) lie apposed to the plasma membrane and are presumably poised to release transmitter. High-output active zones can accommodate more active zone vesicles since they are longer than their low-output counterparts. The greater number of active zone particles at high-output active zones may yield higher local $\mathrm{Ca}^{2+}$ concentrations at the transmitter release sites. Therefore, differences in the number of active zone particles provide a good predictor for the probability of transmitter release at active zones. Active zones are drawn nearly to scale. Magnification, 300,000×.

ger than their low-output counterparts so that there is room for about $50 \%$ more active zone vesicles at distal synapses (Fig. 18). However, the combination of these two factors can account for less than a two fold disparity in epsp amplitude.

The third factor, differences in the number of active zone particles at high- and low-output active zones that can produce overlapping $\mathrm{Ca}^{2+}$ domains, may contribute to the bulk of the proximal-distal disparity in epsp amplitude. At low-output active zones, overlapping $\mathrm{Ca}^{2+}$ domains would result from the simultaneous opening of any of the 14 putative $\mathrm{Ca}^{2+}$ channels (assuming $2.4 \mathrm{msec}$ channel open times and $100 \mathrm{~nm}$ spacing for the overlap). Because not all of the domains at the high-output active zones can overlap, the difference in the probability of transmitter release between high- and low-output active zones would be less than the 5 fold disparity $\left(1.5^{4}=5.1\right)$ suggested by a simple $50 \%$ difference in the number of active zone particles ( 21 vs. 14 particles). For example, depending on its position in the array, a particle in a $150 \mathrm{~nm}$ long active zone could produce between 15 and 20 overlapping domains, and $92 \%$ of the possible combinations of particle pairings in these active zones could form overlapping domains. We estimate that the difference in the number of possible overlapping domains at high- 
and low-output active zones could produce a difference in the probability of transmitter release of about 4.7. The number of ovcrlapping domains that a particle can form reaches a maximum of about 30 in active zones that are more than $200 \mathrm{~nm}$ long. Therefore, increases in active zone length could produce nonlinear increases in the probability of transmitter release that result from increasing the number of overlapping domains and from increasing the number of channels available to produce these domains.

Facilitation and active zone structure. Presynaptic facilitation occurs when the final stimulus in a series of stimuli releases more transmitter than the initial stimulus (Atwood, 1976; Zucker, 1989). In the DAFM, presynaptic facilitation is stronger at synapses on the proximal bundle than at ones on the distal bundle (Meiss and Govind, 1979), and proximal-distal differences in active zone structure may contribute to this disparity. Following a single depolarization, the smaller number of voltage-gated $\mathrm{Ca}^{2+}$ channels at low-output active zones may admit insufficient $\mathrm{Ca}^{2+}$ to occupy enough of the cooperatively acting sites to trigger transmitter release. However, if a second depolarization arrives while some of these $\mathrm{Ca}^{2+}$ binding sites remain occupied, fusion of the active zone vesicle with the plasma membrane may become likely (Sivaramakrishnan et al., 1991b). Alternatively, $\mathrm{Ca}^{2+}$ admitted by the initial depolarization could increase the probability of subsequent voltage-dependent $\mathrm{Ca}^{2+}$ channel opening, and thercby increase the amount of $\mathrm{Ca}^{2+}$ admitted at the active zones during subsequent depolarizations. However, measurements of $\mathrm{Ca}^{2+}$ currents following repeated stimuli have not shown an activity-dependent increase in $\mathrm{Ca}^{2+}$ conductance (Smith and Zucker, 1980; Charlton et al., 1982).

$\mathrm{Ca}^{2+}$ activated $\mathrm{K}^{+}$channels at the active zone. Calcium-activated $\mathrm{K}^{+}$channels appear to be located near neurotransmitter release sites and may mediate membrane repolarization following $\mathrm{Ca}^{2+}$ influx at the active zone (Roberts et al., 1990; Sivaramakrishnan et al., $1991 \mathrm{a}$; Robitaille and Charlton, 1992). This repolarization may affect the open times of voltage-gated $\mathrm{Ca}^{2+}$ channels at facilitated active zones. If $K_{(\mathrm{ra})}$ channels are included among the active zone particles, the proximal-distal disparity in particle number per active zone could help explain why small active zones facilitate more strongly than large ones. The exponential relationship of $\mathrm{Ca}^{2+}$ influx to transmitter release suggests that small changes in $\mathrm{Ca}^{2+}$ channel open times likely produce large changes in the probability of transmitter release. Therefore, a paucity of $\mathrm{K}_{(\mathrm{Ca})}$ channels at low-output active zones could lead to prolongation of $\mathrm{Ca}^{2+}$ currents at these active zones. Such a prolongation at facilitated active zones could increase probabilities of transmitter release to approach those at high output active zones containing more $\mathrm{Ca}^{2+}$ and $\mathrm{K}_{(\mathrm{Ca})}$ channels.

Organization of pre- and postsynaptic membranes. The lack of proximal-distal differences in the size and distribution of intramembrane particles in the postsynaptic membrane suggests that differences in the number of glutamate receptors do not contribute to the proximal-distal difference in epsp amplitude. However, plaque size and hence receptor availability might be important in determining the size of the postsynaptic current produced by a quantum of transmitter.

At crustacean excitatory neuromuscular synapses, 4 molecules of transmitter are thought to be required to open one channel, and the amplitudes of quantal events are distributed normally and vary over a five fold range (Dudel, 1977; for review, see Atwood and Wojtowicz, 1986). Although the source of this variation remains unclear, the predominance of plaque areas between 0.03 and $0.35 \mu \mathrm{m}^{2}$ in the nearly normal distribution of plaque areas suggests that variability in the size of quantal events may result from differences in the number of receptors (Fig. 9). In the larger plaques, receptor site availability may approach the number of transmitter molecules in a quantum. For example, a $0.35 \mu \mathrm{m}^{2}$ plaque would contain over 5000 transmitter binding sites $\left(0.35 \mu \mathrm{m}^{2} \times 3700\right.$ particles per $\mu \mathrm{m}^{2} \times$ 4 binding sites per receptor), and increasing plaque size beyond this level may not affect the size of the postsynaptic quantal event. For plaques smaller than about $0.35 \mu \mathrm{m}^{2}$, transmitter would be in excess of receptor, and the size of the quantal event would be proportional to receptor number (assuming that the probability of channel opening is the same at all plaques).

Presynaptic membranes in the axon terminal are recognized in freeze-fracture views of crustacean synapses as plateaus in the protoplasmic leaflet. Active zones are located on the plateaus, and a plateau may contain several active zones. The plateaus are in register with the postsynaptic plaques, but the plateaus are more than 3 times larger than the plaques. This size disparity and the variability in the position of active zones on the plateau suggests that transmitter release sites need not lie in perfect register with the postsynaptic receptors. Variability in active zone position may not be critical to epsp amplitude since transmitter will diffuse rapidly in the restricted volume of the synaptic cleft, and binding to receptors will limit transmitter diffusion (Mathews-Bellinger and Salpeter, 1978).

\section{Structural adaptations regulating inhibitory transmitter release}

The consistent relationship between active zone structure and the amount of transmitter released in the lobster DAFM as well in the moth (Rheuben, 1985), lizard (Walrond and Reese, 1985), and frog (Propst and Ko, 1987) suggest that the number of active zone particles at a transmitter release site affects the probability of transmitter release. This relationship further suggests that the probability of transmitter release and the degree of facilitation may be homogeneous for neurons with uniformly organized active zones. One mechanism for differentially regulating the amount of transmitter released from such neurons would be to regulate the number of active zones. To examine this possibility, we analyzed the distribution of inhibitory synapses in the DAFM.

For the inhibitor in the DAFM, differences in active zone structure do not appear to be responsible for the proximal-distal difference in inhibitory transmitter release since thin section studies have indicated that active zone size and number per synapse are similar on the proximal and distal muscle fiber bundles in the DAFM (Govind and Pearce, 1989; Walrond et al., 1990). Because most synapses are located in swellings in the axon terminal called varicosities (Jahromi and $\Lambda$ twood, 1974; Florey and Cahill, 1982; Walrond et al., 1990), the number and distribution of inhibitory synapses can be estimated and compared in muscle whole mounts of the proximal and distal muscle fiber bundles stained for the inhibitory neurotransmitter, GABA. This method revealed a proximal-distal disparity in varicosity density. This disparity provided the most obvious characteristic to differentiate the high- and low-output axon branches of the inhibitor, and suggested that the differential release of inhibitory transmitter is regulated by differences in the number of similarly organized active zones. However, a definitive demonstration of the structural equivalence of inhibitory active zones on proximal and distal muscle fibers will require freeze-fracture views of these synapses. 


\section{Conclusions}

In the lobster DAFM, transmitter release is regionally differentiated for the excitatory and the inhibitory motor neuron. Both neurons release more transmitter onto the most distal fiber bundle than onto the most proximal muscle fiber bundle. Different structural adaptations in the two neurons appear to regulate the proximal-distal disparity in synaptic efficacy. For the inhibitor, differences in synapse number appear sufficient to account for the proximal-distal disparity in the amount of transmitter released. For the excitor, synapse number and active zone number per synapse are insufficiently different to account for the several fold proximal-distal disparity in epsp amplitude. Differences in synaptic efficacy that correlate with differences in active zone structure can account for most of the proximaldistal disparity in epsp amplitude. High-output active zones are larger and contain more putative $\mathrm{Ca}^{2+}$ channels capable of producing overlapping $\mathrm{Ca}^{2+}$ domains than their low-output counter parts. Assuming that most of the E-face particles in the postsynaptic membrane represent glutamate receptors, differences in postsynaptic structure do not appear to be important in regulating the proximal-distal differences in synaptic efficacy for the excitor. The results of our studies provide additional, albeit indirect support for the "structure-function" hypothesis for the control of transmitter release, i.e., that the probability for the release of a quantum of transmitter is enhanced by increasing the number of $\mathrm{Ca}^{2+}$ channels that can produce overlapping $\mathrm{Ca}^{2+}$ domains at a transmitter release site.

\section{References}

Adler EM, Augustine GJ, Duffy SN, Charlton MP (1991) Alien intracellular calcium chelators attenuate neurotransmitter release at the squid giant synapse. J Neurosci 11:1496-1507.

Atwood HL (1976) Organization and synaptic physiology of crustacean neuromuscular systems. Prog Neurobiol 7:291-391.

Atwood HL, Lnenicka GA (1986) Structure and function in synapses: emerging correlations. Trends Neurosci 9:248-250.

Atwood HL, Marin L (1983) Ultrastructure of synapses with different transmitter-releasing characteristics on motor axon terminals of a crab, Hyas areneas. Cell Tissue Res 231:103-115.

Atwood HL, Wojtowicz JM (1986) Short-term and long-term plasticity and physiological differentiation of crustacean motor synapses. Intl Rev Neurobiol 28:275-362.

Augustine GJ, Charlton MP (1986) Calcium dependence of presynaptic calcium current and post-synaptic response at the squid giant synapse. J Physiol (Lond) 381:619-640.

Augustine GJ, Adler EM, Charlton MP (1991) The calcium signal for transmitter secretion from presynaptic ner ve terminals. Ann NY Acad Sci 635:365-381.

Charlton MP, Smith SJ, Zucker RS (1982) Role of presynaptic calcium ions and channels in synaptic facilitation and depression at the squid giant synapse. J Physiol (Lond) 323:173-193.

Cohen MW, Jones OT, Angelides KJ (1991) Distribution of $\mathrm{Ca}^{2+}$ channels on frog motor nerve terminals revealed by fluorescent $\omega$-conotoxin. J Neurosci 11:1032-1039.

Couteaux R, Pecot-Dechavassine M (1970) Vesicules synaptiques et poches au niveau des zones actives de la jonction neuromusculaire. Compt Rend Acad Sci (Paris) 271:2346-2349.

Dickinson-Nelson A, Reese TS (1983) Structural changes during transmitter release at synapses in the frog sympathetic ganglion. J Neurosci 3:42-52.

Dryer F, Peper K, Akert K, Sandri C, and Moor H (1973) Ultrastructure of the "active zone" in the frog neuromuscular junction. Brain Res 62:373-380.

Dudel J (1977) Dose-response curve of glutamate applied by superfusion to crayfish muscle synpases. Pflugers Arch 368:49-54.

Engel AG (1991) Review of evidence for loss of motor nerve terminal calcium channels in Lambert-Eaton myasthenic syndrome. Ann NY Acad Sci 635:246-258.
Florey E, Cahill MA (1982) The innervation pattern of crustacean skeletal muscle. Cell Tissue Res 224:527-541.

Franzini-Armstrong C (1976) Freeze-fracture of excitatory and inhibitory synapses in crayfish neuromuscular junctions. J Microsc Biol Cell 25:217-229.

Govind CK, Chiang RG (1979) Correlation hetween synaptic dense bodies and transmitter output at lobster neuromuscular terminals by serial section electron microscopy. Brain Res 161:377-388.

Govind CK, Meiss DE (1979) Quantitative comparison of low- and high-output neuromuscular synapses from a motoneuron of the lobster (Homarus americanus). Cell Tissue Res 198:455-463.

Govind CK, Pearce J (1989) Growth of inhibitory innervation in a lobster muscle. J Morph 199:197-205.

Govind CK, Meiss DE, Pearce J (1982) Differentiation of identifiable lobster neuromuscular synapses during development. J Neurocytol 11:235-247.

Gulley RL, Landis DMD, Reese TS (1978) Internal organization of membranes and end bulbs of Held in the anteroventral cochlear nucleus. J Comp Neurol 180:707-742.

Heuser JE, Reese TS (1973) Evidence for recycling of synaptic vesicle membrane during transmitter release at the frog neuromuscular junction. J Cell Biol 57:315-344.

Heuser JE, Reese TS (1981) Structural changes following transmitter release at the frog neuromuscular junction. J Cell Biol 88:564-580.

Heuser JE, Reese TS, Landis DMD (1974) Functional changes in frog neuromuscular junctions studied with freeze-fracture. J Neurocytol $3: 109-131$.

Heuser JE, Reese TS, Dennis MJ, Jan Y, Jan L, Evans L (1979) Synaptic vesicle exocytosis captured by quick freezing and correlated with quantal transmitter release. J Cell Biol 81:275-300.

Huestis SE, Walrond JP, Govind CK (1989) Two structural mechanisms for regulating neurotransmitter release. Soc Neurosci Abstracts 15:192.

Jahromi SS, Atwood HI. (1974) Three-dimensional ultrastructure of the crayfish neuromuscular apparatus. J Cell Biol 63:599-613.

Johnson CD, Stretton AOW (1987) GABA-immunoreactivity in inhibitory motor neurons of the nematode Ascaris. J Neurosci 7:223235.

Kim YI, Neher E (1988) IgG from patients with Lambert-Eaton syndrome blocks voltage dependent calcium channels. Science 239:405408.

Llinás R, Steinberg IZ, Walton K (1981) Relationship between presynaptic calcium current and postsynaptic potential in squid giant synapse. Biophys J 33:323-351.

Llinás R, Sugimori M, Silver RB (1992) Microdomains of high calcium concentration in a presynaptic terminal. Science 256:677-679.

Mathews-Bellinger J, Salpeter MM (1978) Distribution of acetylcholine receptors at frog neuromuscular junctions with a discussion of some physiological implications. J Physiol (Lond) 279:197-213.

McDonald AJ, Beitz AJ, Larson AA, Kuriyama R, Sellitto C, Madl JE (1989) Co-localization of glutamate and tubulin in putative excitatory neurons of the hippocampus and amygdala: an immunohistochemical study using monoclonal antibodies. Neurosci 30:405-421.

Meiss DE, Govind CK (1979) Regional differentiation of neuromuscular synapses in a lobster receptor muscle. J Exp Biol 79:99-114.

Otsuka M, Iversen LL, Hall ZW, Kravitz EA (1966) Release of gammaaminobutyric acid from inhibitory nerves of lobster. Proc Natl Acad Sci (USA) 56:1110-1115.

Peachey LD (1958) Thin sections: I. A study of section thickness and physical distortion produced during microtomy. J Biophys Biochem Cytol 4:233-242.

Pearce J, Govind CK, Shivers R (1986) Intramembranous organization of lobster excitatory neuromuscular synapses. J Neurocytol 15 : 241-252.

Propst JW, Ko C-P (1987) Correlations between active zone ultrastructure and synaptic function studied with freeze-fracture of physiologically identified neuromuscular junctions. J Neurosci 11:36543664.

Pumplin DW, Reese TS, Llinás R (1981) Are the presynaptic active zone particles the calcium channels? Proc Natl Acad Sci (USA) 78: 7210-7214.

Rheuben MB (1985) Quantitative comparison of the structural features of slow and fast neuromuscular junctions in Manduca. J Neurosci 5:1704-1716.

Rheuben MB, Reese TS (1978) Three-dimensional structure and 
membrane specializations of moth excitatory neuromuscular synapse. J Ultrastruct Res 65:95-111.

Roberts WM, Jacobs RA, Hudspeth AJ (1990) Colocalization of ion channels involved in frequency selectivity and synaptic transmission at presynaptic active zones of hair cells. J Neurosci 10:3664-3684.

Robitaille R, Charlton MP (1992) Presynaptic calcium signals and transmitter release are modulated by calcium-activated potassium channels. J Neurosci 12:297-305.

Robitaille R, Adler EM, Charlton MP (1990) Strategic location of calcium channels at transmitter release sites of frog neuromuscular synapses. Neuron 5:773-779.

Simon SM, I linás R (1985) Compartmentalization of the submembrane calcium activity during calcium influx and its significance in transmitter release. Biophys J 48:485-498.

Sivaramakrishnan S, Bittner GD, Brodwick MS (1991a) Calciumactivated potassium conductance in presynaptic terminals at the crayfish neuromuscular junction. J Gen Physiol 98:1161-1179.

Sivaramakrishnan S, Brodwick MS, Bittner GD (1991b) Presynaptic facilitation at the crayfish neuromuscular junction. J Gen Physiol 98: 1181-1196.
Smith SJ, Zucker RS (1980) Aequorin responsc facilitation and intracellular calcium accumulation in molluscan neurones. J Physiol (Lond) 300:167-196.

Walrond JP, Govind CK (1987) Active zone structure at lobster highand low-output synapses. Soc Neurosci Abstracts 13:317.

Walrond JP, Reese TS (1985) Structure of axon terminals and active zones at synapses on lizard twitch and tonic muscle fibers. J Neurosci 5:1118-1131

Walrond JP, Wiens TJ, Govind CK (1990) Inhibitory innervation of a lobster muscle. Cell Tissue Res 260:421-429.

Wiersma CAG (1961) The neuromuscular system. In: The physiology of Crustacea (Waterman TH, ed), pp 191-240. New York: Academic Press.

Zucker RS (1989) Short-term synaptic plasticity. Ann Rev Neurosci 12:13-31.

Zucker RS, Fogelson AL (1986) Relationship between transmitter release and presynaptic calcium influx when calcium enters through discrete channels. Proc Natl Acad Sci (USA) 83:3032-3036. 